\title{
The Common Acid Sphingomyelinase Polymorphism p.G508R is Associated with Self-Reported Allergy
}

\author{
Martin Reichela Tanja Richter-Schmidinger ${ }^{\mathrm{a}}$ Christiane Mühle ${ }^{\mathrm{a}}$ Cosima Rhein ${ }^{\mathrm{a}}$ \\ Panagiotis Alexopoulos ${ }^{a, b}$ Sibylle G. Schwaba Erich Gulbins ${ }^{c} \quad$ Johannes Kornhuber ${ }^{a}$
}

aDepartment of Psychiatry and Psychotherapy, Friedrich-Alexander-University of Erlangen-Nuremberg, Erlangen, bDepartment of Psychiatry and Psychotherapy, Technical University of Munich, Munich,

'Department of Molecular Biology, University of Duisburg-Essen, Essen, Germany

\section{Key Words}

Acid sphingomyelinase $\cdot$ Allergy $\bullet$ Ceramide $\bullet$ Chronic disease $\cdot$ General health $\bullet$ Infection • Inflammation

\begin{abstract}
Background: Acid sphingomyelinase (ASM) is a key regulator of ceramide-dependent signalling pathways. Among others, activation of ASM can be induced by CD95 or cytokine signalling and by cellular stress resulting from inflammation or infection. Increased ASM activity was observed in a variety of human diseases including inflammatory and neuropsychiatric disorders. We hypothesized that basal ASM activity might influence the susceptibility for common human diseases. Methods: The general health condition of 100 young people was assessed using a questionnaire. The ASM polymorphism rs1050239 (c.1522G > A; encoding p.G508R) was determined from genomic DNA. Activities of secretory (S-) and lysosomal (L-) ASM were measured in blood plasma and peripheral blood cells respectively. Results: The polymorphism rs1050239 was significantly associated with self-reported allergy $\left(p=4.68 \times 10^{-4} ;\right.$ adjusted $p$-value for multiple testing 0.007$)$. Allergy was more prevalent in carriers of the minor A allele compared to non-carriers ( $p=0.00015$; odds ratio $=6.5,95 \% \mathrm{CI} 2.15-21.7$ ). S-ASM activity was significantly associated with rs1050239 $\left(p=5.3 \times 10^{-7}\right)$ and decreased with the number of $A$ alleles in a gene-dosage dependent manner. In allergic patients, S-ASM activity was moderately decreased $(p=0.034)$. L-ASM activity was significantly lower in subjects homozygous for the minor A allele $(p=0.025)$ but not different between allergic and nonallergic subjects $(p=0.318)$. Conclusion: Our analysis provides evidence for an involvement of ASM in the pathophysiology of allergy, which is in line with previous reports addressing the role of sphingolipids in this disorder. Further studies should clarify the mechanism linking rs 1050239 to allergy. The ASM pathway might be useful for predicting allergic disposition and disease course and as a therapeutic target.
\end{abstract}




\section{Introduction}

Acid sphingomyelinase (ASM, EC 3.1.4.12) catalyses the hydrolysis of sphingomyelin, a major lipid component of cellular membranes, into ceramide and phosphorylcholin. Ceramide and its further metabolites sphingosine and sphingosine-1-phosphate act as bioactive molecules and play roles in the regulation of cell growth, cell death, senescence, adhesion, migration, inflammation, angiogenesis and intracellular trafficking [reviewed in $1,2]$.

Ceramide-generating enzymes such as ASM have gained attention as key regulators of ceramide-dependent signalling pathways. Activation of ASM and a concomitant increase in ceramide concentrations can be induced by the stimulation of various receptors, including CD95 or those for tumor necrosis factor (TNF)- $\alpha$, interleukin (IL)-1 $\beta$ or platelet-activating factor, or by cellular stress such as inflammation, infection, ischemia, radiation, oxidative stress, chemotherapeutic agents or cell wounding [3-12]. Increased ASM activity was observed in several human diseases such as chronic heart failure, type 2 diabetes, sepsis, peritonitis, hepatitis, hemophagocytic lymphohistiocytosis, antineutrophil cytoplasmic antibody-associated primary systemic vasculitis, neurodegeneration, depression and alcohol abuse [13-23]. A variety of small organic, drug-like compounds that functionally inhibit ASM are used in the therapy of human diseases [24-26]. In various experimental mouse models, such as lipopolysaccharide (LPS)-, TNF- $\alpha$ - or $\mathrm{Cu}^{2+}$-induced liver damage or alcoholinduced steatosis, genetic deficiency or pharmacological inhibition of ASM was associated with beneficial outcome [27-30]. A reduction in ASM activity also normalized pulmonary ceramide levels and infection susceptibility in a mouse model of cystic fibrosis [30,31]. Taken together, these reports suggest that ASM hyperfunction could be a risk factor for human health. However, ASM-dependent sphingomyelin degradation is an essential cellular process. An inherited deficiency of ASM causes the lysosomal storage disorder Niemann-Pick disease [32], which is characterized by the accumulation of sphingomyelin in the endolysosomal compartment. Patients often present hepatosplenomegaly, respiratory complications, atherogenic lipid profiles and sometimes progressive neurodegeneration [33]. In addition, ASM plays a pivotal role in the host defense against pathogens and metastasising cancer [8, $34,35]$. Thus, a balanced activity of ASM seems to be beneficial to maintain human health.

ASM is a glycoprotein located in the endolysosomal compartment, in secretory vesicles and at the outer leaflet of the plasma membrane [36]. The enzyme is also present in various human body fluids including blood serum [37,38]. Despite the broad evidence for an involvement of ASM in human diseases, little is known about the regulation of the basal ASM activity and its importance for human health. We hypothesized that the individual ASM activity is a constitutive trait that, even within the normal range, influences contextdependent ceramide-induced signalling pathways, thereby altering susceptibility for human diseases. For the analysis, we defined individual ASM constitution as the secretory (S-) ASM activity from blood plasma, the lysosomal (L-) ASM activity from peripheral blood cells, and the genotype of the common ASM polymorphism rs1050239. These data were compared with the prevalence of common human diseases in a sample of 100 young participants. Our analysis revealed evidence for an genetic association of ASM with allergy.

\section{Materials and Methods}

\section{Study sample}

The study sample consisted of 100 young people that had participated in the GENES study [39, 40]. Study subjects were free of somatic diseases potentially affecting brain function, past or current mental disorders, regular intake of drugs (except hormonal contraceptives), abuse of mind-altering substances (except moderate consumption of alcohol) and were not pregnant. Participants in addition filled out a general health questionnaire that was sent to them one year after the first examination. All participants were recruited through the Department of Psychiatry and Psychotherapy of the University Hospital Erlangen and 
signed the Patient Information Protocol and an Informed Consent Statement. The study was conducted in accordance with the 2008 Declaration of Helsinki and was approved by the Ethics Committee of the Medical Faculty of the Friedrich-Alexander University Erlangen-Nuremberg.

General health survey

To determine the general health condition of the participants a set of health related questions that could be answered by self-assessment were extracted from the literature and compiled into a questionnaire by a psychologist specialized in test psychology. The complete questionnaire (http://opus4.kobv.de/opus4fau/frontdoor/index/index/docld/4654) covered four aspects of health (protective and risk factors; infectious diseases; chronic disorders; current well-being). For the question addressed in this study only the parts assessing the prevalence of infectious diseases and chronic disorders were relevant and considered for analyses.

Determination of ASM activity

S-ASM and L-ASM activities were assessed from blood plasma and peripheral blood mononuclear cells respectively, as previously described [21,22].

Genetic analysis

Genomic DNA was isolated from whole blood using the Gentra Puregene Blood Kit (Qiagen, Hilden, Germany) according to the supplier's protocol. Genotyping of the ASM polymorphism rs1050239 was performed using polymerase chain reaction and restriction fragment length polymorphism analysis with the forward oligonucleotide $5^{\prime}$-TCCTGGAGTTGGTGGGATAG-3' and reverse oligonucleotide $5^{\prime}$-GGTATGTTTGCCTGGGTCAG-3'. The 227 bp PCR product was digested with the restriction enzyme Ncil (New England Biolabs, Frankfurt am Main, Germany) according to the manufacturer's protocol. The fragments were separated on a 3\% agarose gel and visualized using ethidium bromide staining and UV light. The PCR product derived from the major G allele (c.1522G; encoding ASM Gly ${ }^{508}$ ) was cleaved into two fragments (162 and $67 \mathrm{bp}$ ), whereas that from the minor A allele (c.1522A; encoding Arg ${ }^{508}$ ) was not cleaved. Genotyping for each sample was performed twice with $100 \%$ confirmation. The distribution of genotypes (GG, $n=52$; $G A, n=42 ; A A, n=6$ ) did not deviate from the Hardy-Weinberg equilibrium (chisquared test: $\mathrm{p}=0.807)$.

\section{Statistical analyses}

Statistical analyses were performed with the software package IBM SPSS Statistics 19. Health conditions were analyzed as nominal-scaled variables with two levels (infections at least once a year: "yes" or "no"; complications during the course of infections: "yes" or "no"; presence of chronic diseases: "yes" or "no"). The genetic variable rs1050239 was used ordinally, scaled with three levels represented by the three genotypes GG, GA and AA. S- and L-ASM activities were used as metric continuous variables. Associations were analyzed by ANOVA and significant results were tested for confounding effects of sex and age. All other tests used are given with the results. A p-value $\leq 0.05$ was considered to indicate significance. Adjustment for multiple comparisons was conducted by Bonferroni correction.

\section{Results}

To test the hypothesis that basal ASM activity relates to the susceptibility for common human diseases, we assessed the general health condition of 100 young people (33 males, 67 females; mean age \pm SD: $24.1 \pm 3.1$ years) using a self-assembled questionnaire (see method section). Participants were asked whether they suffer regularly from any of 11 given infectious diseases, any of seven given complications accompanying infections or any of 16 given chronic diseases. Fifteen interrogated health issues (43\%) were prevalent in our sample with a frequency $>5 \%$ and were selected for further analysis (Table 1 ). The other twenty items (57\%) were answered by $\geq 95 \%$ of the participants with the same value and omitted from further analysis. 
Reichel et al.: ASM p.G508R is Associated with Allergy

Table 1. Association of health issues with the ASM status. Self-reported health-issues with a prevalence of $>5 \%$ in the study sample are shown together with their p-values generated from ANOVA (rs1050239: one-way ANOVA; S- and L-ASM activities: multifactorial ANOVA with sex and age as covariates). Significant results are indicated in bold. Arrows indicate increased and decreased activity in affected vs. not affected subjects. ASM, acid sphingomyelinase; L-ASM, lysosomal ASM; S-ASM, secretory ASM

\begin{tabular}{|c|c|c|c|c|}
\hline Health issue & Prevalence $(\%)$ & rs1050239 & S-ASM & L-ASM \\
\hline \multicolumn{5}{|c|}{ Do you suffer at least once a year from any of these infection diseases? } \\
\hline Pyrexia & 44 & 0.257 & 0.720 & 0.187 \\
\hline Cough & 69 & 0.399 & 0.785 & 0.410 \\
\hline Cold & 92 & 0.695 & 0.914 & 0.293 \\
\hline Infections of the upper respiratory tract & 35 & 0.062 & 0.184 & 0.562 \\
\hline Infections of the lower respiratory tract & 16 & 0.551 & $0.012(\downarrow)$ & 0.357 \\
\hline Infections of the skin & 8 & 0.725 & 0.434 & 0.619 \\
\hline Infections of the gastrointestinal tract & 26 & 0.155 & $0.008(\uparrow)$ & 0.094 \\
\hline Infections of the urinary passage & 13 & 0.141 & 0.888 & 0.284 \\
\hline Swelling of the lymph nodes & 24 & 0.501 & 0.068 & 0.977 \\
\hline \multicolumn{5}{|c|}{ Are infectious diseases normally associated with any of these complications? } \\
\hline Difficulty recovering from infections & 10 & 0.650 & 0.266 & 0.713 \\
\hline Regular treatment with antibiotics & 6 & 0.284 & 0.504 & 0.095 \\
\hline Expansion to frontal sinuses or middle ear & 22 & 0.273 & 0.382 & 0.785 \\
\hline Frequent feeling of tiredness & 24 & 0.341 & 0.675 & $0.029(\uparrow)$ \\
\hline \multicolumn{5}{|c|}{ Were you diagnosed with any of these chronic disease? } \\
\hline Chronic skin inflammation & 7 & 0.254 & 0.844 & $0.023(\uparrow)$ \\
\hline Allergic asthma, hay fever, allergic skin rash & 28 & $4.7 \times 10^{-4}$ & $0.034(\downarrow)$ & 0.318 \\
\hline
\end{tabular}

The genetic influence of ASM on the prevalence of common human health issues was tested by ANOVA with the respective health issue as dependent variable and the polymorphism rs1050239 as independent variable. These analyses revealed a strong association of rs1050239 with allergy (one-way ANOVA: $\mathrm{F}=8.305, \mathrm{df}=2, \mathrm{p}=4.68 \times 10^{-4}$ ) that was not confounded by age or sex (data not shown). The $\mathrm{p}$-value for this association remained significant after adjustment for multiple comparison ( $\mathrm{p}=0.007)$. A detailed analysis revealed that the prevalence of allergy was 45\% in subjects heterozygous for rs 1050239 (19 allergic patients out of 42 participants with the genotype GA), 50\% in subjects homozygous for the minor A allele ( 3 out of 6 ), and $12 \%$ in subjects homozygous for the major G allele ( 6 out of 52) (Fig. 1A). Therefore, allergy was more prevalent in carriers of the minor A allele of rs1050239 compared to non-carriers of this allele (Fisher's exact test: $p$ value $=0.00015$; odds ratio $=6.5,95 \%$ CI 2.15-21.7).

We next analyzed whether rs1050239 had an influence on the L- or S-ASM activity determined from blood cells and blood plasma respectively. The activities of S- and L-ASM in our sample did not deviate from a normal distribution with means $( \pm \mathrm{SD})$ of $1.82( \pm 0.58)$ $\mathrm{nmol} / \mathrm{mg} / \mathrm{h}$ and $200( \pm 69) \mathrm{pmol} / \mathrm{ml} / \mathrm{h}$ respectively (Kolmogorov-Smirnov test: $\mathrm{p}=0.419$ and 0.471 ). S-ASM activity was slightly higher in females compared to males (males, $\mathrm{n}=33$ : $180 \pm 68 \mathrm{pmol} / \mathrm{ml} / \mathrm{h}$; females, $\mathrm{n}=67: 210 \pm 68 \mathrm{pmol} / \mathrm{ml} / \mathrm{h}$; t-test: $\mathrm{p}=0.042$ ), and both $\mathrm{S}$ - and L-ASM activities correlated modestly with age (L-ASM: Pearson $r=0.198, p=0.048$; S-ASM: $\mathrm{r}=0.218, \mathrm{p}=0.029)$. The correlation between $\mathrm{S}$ - and L-ASM activities was not significant $(\mathrm{r}=0.189, \mathrm{p}=0.060)$.

Of note, S-ASM activity associated significantly with rs1050239 (one-way ANOVA: $\mathrm{F}=16.845, \mathrm{df}=2, \mathrm{p}=5.3 \times 10^{-7}$ ) (Fig. 1B). S-ASM activity was highest in subjects with the genotype GG $(230 \pm 66 \mathrm{pmol} / \mathrm{ml} / \mathrm{h} ; \mathrm{n}=52)$, intermediate in heterozygous subjects $(176 \pm 53$ $\mathrm{pmol} / \mathrm{ml} / \mathrm{h} ; \mathrm{n}=42)$ and lowest in subjects homozygous for the A allele $(109 \pm 48 \mathrm{pmol} /$ $\mathrm{ml} / \mathrm{h} ; \mathrm{n}=6$ ). Post-hoc analysis revealed significant differences between all three genotypes (Bonferroni: GG vs. GA: $\mathrm{p}=1.09 \times 10^{-4}$; GG vs. AA: $\mathrm{p}=2.51 \times 10^{-5}$; GA vs AA: $\mathrm{p}=0.033$ ). The genetic effect on S-ASM activity was similar for male and female participants and was not influenced by age (data not shown). L-ASM activity was not significantly associated with rs1050239 


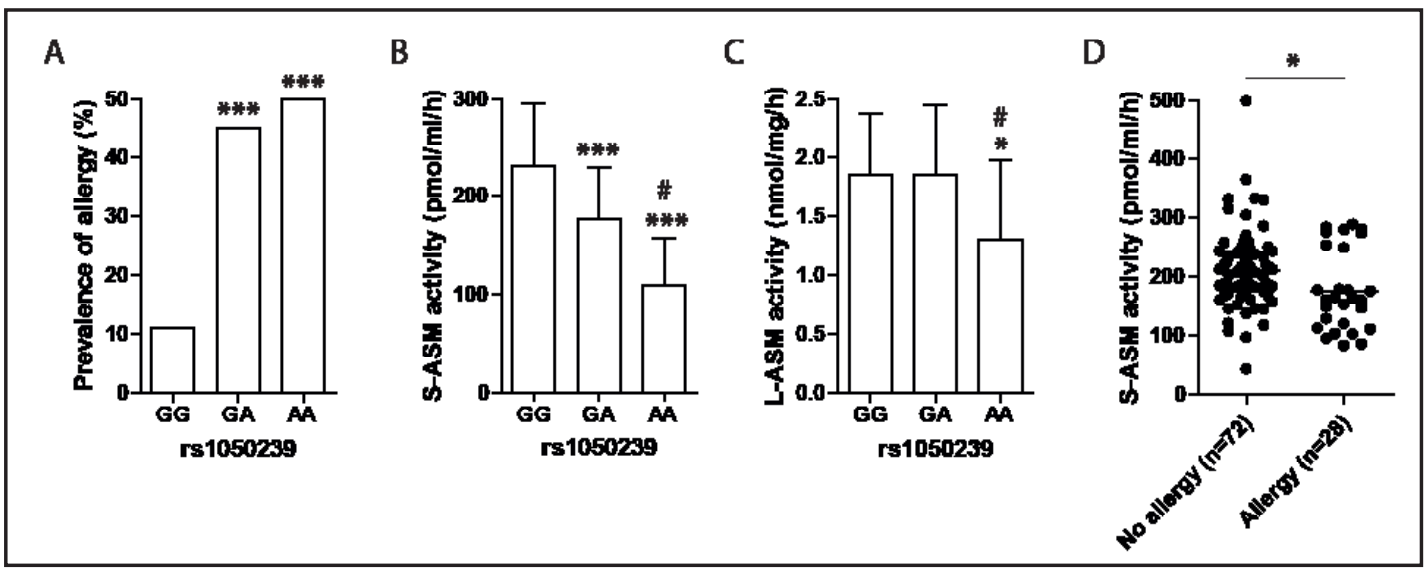

Fig. 1. Association of the polymorphism rs1050239 (c.1522G>A) encoding the ASM variant p.G508R with self-reported allergy and ASM activity. (A) The prevalence of allergy was higher in carriers of the minor A allele compared to non-carriers. (B) The ASM polymorphism rs1050239 was strongly associated with S-ASM activity in blood serum. (C) L-ASM activity was lower in subjects homozygous for the minor A allele compared to the two other genotypes. (D) Participants diagnosed with allergy $(n=28)$ presented with significantly lower S-ASM activity in the blood plasma than people not reporting allergy $(\mathrm{n}=72)$. Columns represent mean values and error bars standard deviation. ASM, acid sphingomyelinase; L-ASM, lysosomal ASM; S-ASM, secretory ASM. Asterisks in panels A-C indicate significant differences compared to genotype GG (Bonferroni post hoc: * p-value $<0.05$; ${ }^{* * *}$ p-value $<0.001$ ), and hashes significant difference compared to genotype GA.

in the genotype comparison (one-way ANOVA: $\mathrm{F}=2.547, \mathrm{df}=2, \mathrm{p}=0.084$ ). However, L-ASM activity was significantly lower in subjects homozygous for the minor A allele in comparison to the two other genotypes (AA: $1.31 \pm 0.67 \mathrm{nmol} / \mathrm{mg} / \mathrm{h}, \mathrm{n}=6$; GG/GA: $1.85 \pm 0.56 \mathrm{nmol} / \mathrm{mg} / \mathrm{h}$, $\mathrm{n}=94$; one-way ANOVA: $\mathrm{F}=5.146, \mathrm{df}=1, \mathrm{p}=0.025$ ) (Fig. 1C).

Given that rs1050239 associated significantly with allergy and ASM activity, we wondered whether allergy would also be associated with S- or L-ASM activity. An ANOVA with health issues as dependent variable and both S- and L-ASM activities as independent variables revealed a significant association of allergy with S-ASM activity that was independent of the influence of sex or age $(\mathrm{p}=0.034)$ (Table 1$)$. L-ASM activity was not associated with allergy $(\mathrm{p}=0.318)$. S-ASM activity was decreased by $17 \%$ in subjects with allergy compared to not affected subjects (allergy: $175 \pm 69 \mathrm{pmol} / \mathrm{ml} / \mathrm{h}, \mathrm{n}=28$; no allergy: $210 \pm 67, \mathrm{n}=72$; Figure 1D). Of note, when rs1050239 was considered as a covariate, the association of allergy with S-ASM activity was no longer significant (data not shown), indicating that the decreased S-ASM activity in allergic participants is due to association with the rs1050239 polymorphism.

Besides allergy, four additional self-reported health issues were associated either with S- or L-ASM activity in our survey (Table 1). However, these diseases did not associate with the rs1050239 genetic marker.

\section{Discussion}

Activation of ASM is observed in various experimental settings and in a variety of human diseases and is thus considered a promising target for therapeutic intervention [26]. While it is widely accepted that ASM is an important regulator of the host response to harmful stress, little is known about how the basal ASM activity affects this response and the establishment of related diseases. Experimental work using animal models of genetic or pharmacological ASM deficiency have provided good evidence that ASM status can affect host susceptibility for different diseases [8, 30, 41-44]. However, clear evidences of whether/how ASM responses influence disease liability in human are missing. 
To address this we developed a general health survey that can be conducted by selfassessment and which is thus suitable for the screening of larger cohorts. We used the survey to quantify the general health condition of 100 study subjects and to determine the relationship with the basic ASM constitution. The individual ASM status was characterized by the ASM genotype with respect to the polymorphism rs1050239, as well as the S-ASM and L-ASM activity from blood plasma and blood cells respectively.

Using this approach we found evidence that allergy might be genetically linked to ASM. Carriers of the minor A allele of rs1050239 reported significantly more often to be diagnosed with symptoms of allergy than people homozygous for the $G$ allele. We observed no difference in the prevalence of allergy comparing heterozygous subjects with subjects homozygous for the minor A allele, suggesting this allele is an allergy risk factor. Rs1050239 represents the most frequent polymorphism in the coding region of the mature ASM enzyme and encodes an exchange at the amino acid position 508. Although the molecular consequences of this transition have not been studied in detail, the transition is adjacent to a potential phosphorylation site that was reported to be involved in the enzyme's activation and secretion $[45,46]$. Due to the replacement of an uncharged glycine residue by a charged amino acid, the substitution Gly508>Arg508 might affect the respective phosphorylation site recognition motif. Although the clinical significance of rs1050239 has still to be proven, carriers of the minor allele were reported to exhibit altered plasma cholesterol concentrations and an increase in family history of coronary artery disease [47].

Our analysis further revealed that rs1050239 is associated with blood plasma S-ASM activity. It can be assumed that this activity mainly reflects the amount of the ASM enzyme in the analyzed specimen. In addition, post-translational or conformational modifications may change the specific enzymatic activity $[46,48]$ and thus contribute to the total activity determined in the clinical samples. We found that rs1050239 associates with S-ASM activity in a gene-dosage dependent manner. Heterozygous subjects displayed intermediate S-ASM activity levels, while subjects homozygous for the minor A allele displayed half the activity found in subjects homozygous for the major $\mathrm{G}$ allele. These results suggest that rs1050239 might influence the in vivo secretion of ASM through interference with the adjacent phosphorylation site. However, it is also possible that the molecular exchange affects protein stability and/or activation. Whether rs1050239 also affects L-ASM activity remains unclear. Although we observed that L-ASM activity was lowest in the AA genotype group, the p value was moderate. Therefore, further studies will be required to determine if rs1050239 affects L-ASM.

Subjects with allergy also presented with decreased S-ASM activity compared to participants not affected by allergy. This observation might be attributed to the genetic association of the minor A allele with allergy, and does not necessarily imply that decreased S-ASM levels are involved in the pathomechanism leading to allergy. Compared to the strong genetic association we observed, the association of S-ASM with allergy was only moderate. Therefore, the genetic effect of rs1050239 might be mediated by mechanisms other than the regulation of S-ASM abundance in the blood. It is also possible that the genetic effect is not directly mediated by rs1050239, but by another polymorphism associated with the minor A allele, or that the genetic effect is not mediated by ASM.

An involvement of ASM in allergy and asthma has been previously reported. Stimulation of murine mast cells with antigen resulted in increased L-ASM activity [49]. The same study demonstrated that genetic deficiency of ASM impairs the antigen-triggered $\mathrm{Ca}^{2+}$ release from internal stores, the release of $\beta$-hexosaminidase and the antigen-induced migration of mast cells. Systemic anaphylaxis assessed by the decline in body temperature was also less pronounced in ASM-deficient mice [49]. Clustering of CD40 on B cells, which is involved in the signal cascade triggering the class switch to IgE, requires the clustering of CD40 ligand, which in turn involves the activation and translocation of ASM to the plasma membrane [50]. In a clinical study, increased levels of sphingomyelin and an increased activity of ASM was detected in the erythrocyte membrane of asthmatic patients [51]. Further experimental 
studies revealed increased ceramide levels and a role of the glycosphingolipid pathway in airway hyperresponsiveness and asthma [52,53]. Taken together, these reports imply that allergy susceptibility increases with ASM hyperactivity. How this fits together with the genetic association of rs1050239 with allergy susceptibility is not clear. To answer this question, further studies addressing the cellular consequences of rs1050239, especially under challenging conditions such as allergic reaction, are certainly necessary.

In our survey, in addition to allergy other health issues were found to be associated with L- or S-ASM activity. For example, decreased S-ASM activity was associated with the susceptibility for infections of the lower respiratory tract, which is a common complication in patients with Niemann-Pick disease $[54,55]$. This might indicate that a low basal ASM activity compromises the host defense against bacterial infections. However, the p values of the associations we observed were modest and not sufficiently robust to survive multiple testing. In addition, there was no association with the ASM genotype, and thus the direction of the relationship is unclear.

Limitations of our study include that it was conducted as a monocentric study with a relatively small number of cases, and that the health issues were self-reported without a detailed clinical classification. In our analysis, participants diagnosed with allergic asthma, hay fever or allergic skin rash were subsumed as allergic patients. The detailed respective diagnosis, the current medication or the causative antigen was not assessed by the survey. Furthermore, additional allergy types, such as food allergy, were not addressed. Future studies involving a detailed medical history will therefore be necessary to verify and to specify our findings.

In summary, we provide evidence that the ASM pathway plays a role in the pathophysiology of allergy. This is in agreement with other clinical and preclinical reports about the involvement of sphingolipids in the disease. The ASM pathway might be used to predict allergic disposition and to define new therapeutic targets. A better understanding of the molecular changes associated with the ASM coding variant rs1050239 might give new insights into the pathomechanisms leading to allergy.

\section{Disclosure Statement}

None

\section{Acknowledgements}

The authors thank Michaela Schäfer and Stefan Hofmann for excellent technical assistance. The work was supported by funding from the Deutsche Forschungsgemeinschaft grants GU335/23-1 and KO 947/11-1. We acknowledge support by Deutsche Forschungsgemeinschaft and Friedrich-Alexander-Universität Erlangen-Nürnberg (FAU) within the funding programme Open Access Publishing.

\section{References}

1 Hannun YA, Obeid LM: Principles of bioactive lipid signalling: lessons from sphingolipids. Nat Rev Mol Cell Biol 2008;9:139-150.

2 Gulbins E, Li PL: Physiological and pathophysiological aspects of ceramide. Am J Physiol Regul Integr Comp Physiol 2006;290:R11-R26.

3 Santana P, Peña LA, Haimovitz-Friedman A, Martin S, Green D, McLoughlin M, Cordon-Cardo C, Schuchman EH, Fuks Z, Kolesnick R: Acid sphingomyelinase-deficient human lymphoblasts and mice are defective in radiation-induced apoptosis. Cell 1996;86:189-199. 
4 Hofmeister R, Wiegmann K, Korherr C, Bernardo K, Krönke M, Falk W: Activation of acid sphingomyelinase by interleukin-1 (IL-1) requires the IL-1 receptor accessory protein. J Biol Chem 1997;272:27730-27736.

5 Schütze S, Potthoff K, Machleidt T, Berkovic D, Wiegmann K, Krönke M: TNF activates NF-kappa B by phosphatidylcholine-specific phospholipase C-induced "acidic" sphingomyelin breakdown. Cell 1992;71:765-776.

6 Wong ML, Xie B, Beatini N, Phu P, Marathe S, Johns A, Gold PW, Hirsch E, Williams KJ, Licinio J, Tabas I: Acute systemic inflammation up-regulates secretory sphingomyelinase in vivo: a possible link between inflammatory cytokines and atherogenesis. Proc Natl Acad Sci U S A 2000;97:8681-8686.

-7 Grassmé H, Jekle A, Riehle A, Schwarz H, Berger J, Sandhoff K, Kolesnick R, Gulbins E: CD95 signaling via ceramide-rich membrane rafts. J Biol Chem 2001;276:20589-20596.

-8 Grassmé H, Jendrossek V, Riehle A, von Kürthy G, Berger J, Schwarz H, Weller M, Kolesnick R, Gulbins E: Host defense against Pseudomonas aeruginosa requires ceramide-rich membrane rafts. Nat Med 2003;9:322-330.

-9 Tam C, Idone V, Devlin C, Fernandes MC, Flannery A, He X, Schuchman E, Tabas I, Andrews NW: Exocytosis of acid sphingomyelinase by wounded cells promotes endocytosis and plasma membrane repair. J Cell Biol 2010;189:1027-1038.

10 Zhang AY, Yi F, Jin S, Xia M, Chen QZ, Gulbins E, Li PL: Acid sphingomyelinase and its redox amplification in formation of lipid raft redox signaling platforms in endothelial cells. Antioxid Redox Signal 2007;9:817828.

11 Mathias S, Younes A, Kan CC, Orlow I, Joseph C, Kolesnick RN: Activation of the sphingomyelin signaling pathway in intact EL4 cells and in a cell-free system by IL-1 beta. Science 1993;259:519-522.

-12 Göggel R, Winoto-Morbach S, Vielhaber G, Imai Y, Lindner K, Brade L, Brade H, Ehlers S, Slutsky AS, Schütze S, Gulbins E, Uhlig S: PAF-mediated pulmonary edema: a new role for acid sphingomyelinase and ceramide. Nat Med 2004;10:155-160.

13 Quintern LE, Zenk TS, Sandhoff K: The urine from patients with peritonitis as a rich source for purifying human acid sphingomyelinase and other lysosomal enzymes. Biochim Biophys Acta 1989;1003:121-124.

-14 Doehner W, Bunck AC, Rauchhaus M, von Haehling S, Brunkhorst FM, Cicoira M, Tschope C, Ponikowski P, Claus RA, Anker SD: Secretory sphingomyelinase is upregulated in chronic heart failure: a second messenger system of immune activation relates to body composition, muscular functional capacity, and peripheral blood flow. Eur Heart J 2007;28:821-828.

15 Claus RA, Bunck AC, Bockmeyer CL, Brunkhorst FM, Lösche W, Kinscherf R, Deigner HP: Role of increased sphingomyelinase activity in apoptosis and organ failure of patients with severe sepsis. FASEB J 2005;19:1719-1721.

-16 He X, Huang Y, Li B, Gong CX, Schuchman EH: Deregulation of sphingolipid metabolism in Alzheimer's disease. Neurobiol Aging 2010;31:398-408.

17 Jenkins RW, Clarke CJ, Lucas JT, Jr., Shabbir M, Wu BX, Simbari F, Mueller J, Hannun YA, Lazarchick J, Shirai $\mathrm{K}$ : Evaluation of the role of secretory sphingomyelinase and bioactive sphingolipids as biomarkers in hemophagocytic lymphohistiocytosis. Am J Hematol 2013;

18 Takahashi T, Abe T, Sato T, Miura K, Takahashi I, Yano M, Watanabe A, Imashuku S, Takada G: Elevated sphingomyelinase and hypercytokinemia in hemophagocytic lymphohistiocytosis. J Pediatr Hematol Oncol 2002;24:401-404.

19 Górska M, Baranczuk E, Dobrzyn A: Secretory $Z^{2+}{ }^{2+}$ dependent sphingomyelinase activity in the serum of patients with type 2 diabetes is elevated. Horm Metab Res 2003;35:506-507.

-20 Kornhuber J, Medlin A, Bleich S, Jendrossek V, Henkel AW, Wiltfang J, Gulbins E: High activity of acid sphingomyelinase in major depression. J Neural Transm 2005;112:1583-1590.

-21 Reichel M, Greiner E, Richter-Schmidinger T, Yedibela Ö, Tripal P, Jacobi A, Bleich S, Gulbins E, Kornhuber $\mathrm{J}$ : Increased acid sphingomyelinase activity in peripheral blood cells of acutely intoxicated patients with alcohol dependence. Alcohol Clin Exp Res 2010;34:46-50.

22 Reichel M, Beck J, Mühle C, Rotter A, Bleich S, Gulbins E, Kornhuber J: Activity of secretory sphingomyelinase is increased in plasma of alcohol-dependent patients. Alcohol Clin Exp Res 2011;35:1852-1859.

-23 Kiprianos AP, Morgan MD, Little MA, Harper L, Bacon PA, Young SP: Elevated active secretory sphingomyelinase in antineutrophil cytoplasmic antibody-associated primary systemic vasculitis. Ann Rheum Dis 2012;71:1100-1102. 
Reichel et al.: ASM p.G508R is Associated with Allergy

24 Kornhuber J, Muehlbacher M, Trapp S, Pechmann S, Friedl A, Reichel M, Mühle C, Terfloth L, Groemer TW, Spitzer GM, Liedl KR, Gulbins E, Tripal P: Identification of novel functional inhibitors of acid sphingomyelinase. PLOS ONE 2011;6:e23852.

25 Kornhuber J, Tripal P, Reichel M, Terfloth L, Bleich S, Wiltfang J, Gulbins E: Identification of new functional inhibitors of acid sphingomyelinase using a structure-property-activity relation model. J Med Chem 2008;51:219-237.

26 Kornhuber J, Tripal P, Reichel M, Mühle C, Rhein C, Muehlbacher M, Groemer TW, Gulbins E: Functional Inhibitors of Acid Sphingomyelinase (FIASMAs): a novel pharmacological group of drugs with broad clinical applications. Cell Physiol Biochem 2010;26:9-20.

27 Lang PA, Schenck M, Nicolay JP, Becker JU, Kempe DS, Lupescu A, Koka S, Eisele K, Klarl BA, Rubben H, Schmid KW, Mann K, Hildenbrand S, Hefter H, Huber SM, Wieder T, Erhardt A, Haussinger D, Gulbins E, Lang F: Liver cell death and anemia in Wilson disease involve acid sphingomyelinase and ceramide. Nat Med 2007;13:164-170.

28 García-Ruiz C, Colell A, Marí M, Morales A, Calvo M, Enrich C, Fernández-Checa JC: Defective TNF- $\alpha$ mediated hepatocellular apoptosis and liver damage in acidic sphingomyelinase knockout mice. J Clin Invest 2003;111:197-208.

-29 Liangpunsakul S, Rahmini Y, Ross RA, Zhao Z, Xu Y, Crabb DW: Imipramine blocks ethanol-induced ASMase activation, ceramide generation, and PP2A activation, and ameliorates hepatic steatosis in ethanol-fed mice. Am J Physiol Gastrointest Liver Physiol 2012;302:G515-G523.

-30 Teichgräber V, Ulrich M, Endlich N, Riethmüller J, Wilker B, De Oliveira-Munding CC, van Heeckeren AM, Barr ML, von Kürthy G, Schmid KW, Weller M, Tümmler B, Lang F, Grassmé H, Döring G, Gulbins E: Ceramide accumulation mediates inflammation, cell death and infection susceptibility in cystic fibrosis. Nat Med 2008;14:382-391.

31 Becker KA, Riethmuller J, Lüth A, Doring G, Kleuser B, Gulbins E: Acid sphingomyelinase inhibitors normalize pulmonary ceramide and inflammation in cystic fibrosis. Am J Respir Cell Mol Biol 2010;42:716724.

-32 Brady RO, Kanfer JN, Mock MB, Fredrickson DS: The metabolism of sphingomyelin, II. Evidence of an enzymatic deficiency in Niemann-Pick disease. Proc Natl Acad Sci U S A 1966;55:366-369.

-33 Schuchman EH: The pathogenesis and treatment of acid sphingomyelinase-deficient Niemann-Pick disease. J Inherit Metab Dis 2007;30:654-663.

34 Carpinteiro A, Dumitru C, Schenck M, Gulbins E: Ceramide-induced cell death in malignant cells. Cancer Lett 2008;264:1-10.

35 Osawa Y, Suetsugu A, Matsushima-Nishiwaki R, Yasuda I, Saibara T, Moriwaki H, Seishima M, Kozawa O: Liver acid sphingomyelinase inhibits growth of metastatic colon cancer. J Clin Invest 2013;123:834-843.

-36 Jenkins RW, Canals D, Hannun YA: Roles and regulation of secretory and lysosomal acid sphingomyelinase. Cell Signal 2009;21:836-846.

-37 Takahashi I, Takahashi T, Abe T, Watanabe W, Takada G: Distribution of acid sphingomyelinase in human various body fluids. Tohoku J Exp Med 2000;192:61-66.

-38 Mühle C, Huttner HB, Walter S, Reichel M, Canneva F, Lewczuk P, Gulbins E, Kornhuber J: Characterization of acid sphingomyelinase activity in human cerebrospinal fluid. PLOS ONE 2013;8:e62912.

39 Alexopoulos P, Richter-Schmidinger T, Horn M, Maus S, Reichel M, Sidiropoulos C, Rhein C, Lewczuk P, Doerfler A, Kornhuber J: Hippocampal volume differences between healthy young apolipoprotein E $\varepsilon 2$ and $\varepsilon 4$ carriers. J Alzheimers Dis 2011;26:207-210.

40 Richter-Schmidinger T, Alexopoulos P, Horn M, Maus S, Reichel M, Rhein C, Lewczuk P, Sidiropoulos C, Kneib T, Perneczky R, Doerfler A, Kornhuber J: Influence of brain-derived neurotrophic-factor and apolipoprotein E genetic variants on hippocampal volume and memory performance in healthy young adults. J Neural Transm 2011;118:249-257.

41 Gassert E, Avota E, Harms H, Krohne G, Gulbins E, Schneider-Schaulies S: Induction of membrane ceramides: a novel strategy to interfere with T lymphocyte cytoskeletal reorganisation in viral immunosuppression. PLOS Pathog 2009;5:e1000623.

42 Nakatsuji T, Tang DC, Zhang L, Gallo RL, Huang CM: Propionibacterium acnes CAMP factor and host acid sphingomyelinase contribute to bacterial virulence: potential targets for inflammatory acne treatment. PLOS ONE 2011;6:e14797. 


\section{Cellular Physiology $\quad$ Cell Physiol Biochem 2014;34:82-91 and Biochemistry

43 Ng CG, Griffin DE: Acid sphingomyelinase deficiency increases susceptibility to fatal alphavirus encephalomyelitis. J Virol 2006;80:10989-10999.

44 Roca FJ, Ramakrishnan L: TNF dually mediates resistance and susceptibility to mycobacteria via mitochondrial reactive oxygen species. Cell 2013;153:521-534.

45 Jenkins RW, Canals D, Idkowiak-Baldys J, Simbari F, Roddy P, Perry DM, Kitatani K, Luberto C, Hannun YA: Regulated secretion of acid sphingomyelinase: implications for selectivity of ceramide formation. J Biol Chem 2010;285:35706-35718.

-46 Zeidan YH, Hannun YA: Activation of acid sphingomyelinase by protein kinase C $\delta$-mediated phosphorylation. J Biol Chem 2007;282:11549-11561.

47 Dastani Z, Ruel IL, Engert JC, Genest J Jr, Marcil M: Sphingomyelin phosphodiesterase-1 (SMPD1) coding variants do not contribute to low levels of high-density lipoprotein cholesterol. BMC Med Genet 2007;8:79.

48 Qiu H, Edmunds T, Baker-Malcolm J, Karey KP, Estes S, Schwarz C, Hughes H, Van Patten SM: Activation of human acid sphingomyelinase through modification or deletion of C-terminal cysteine. J Biol Chem 2003;278:32744-32752.

-49 Yang W, Schmid E, Nurbaeva MK, Szteyn K, Leibrock C, Yan J, Schaller M, Gulbins E, Shumilina E, Lang F: Role of acid sphingomyelinase in the regulation of mast cell function. Clin Exp Allergy 2014;44:79-90.

50 Grassmé H, Bock J, Kun J, Gulbins E: Clustering of CD40 ligand is required to form a functional contact with CD40. J Biol Chem 2002;277:30289-30299.

51 Gupta P, Vijayan VK, Bansal SK: Sphingomyelin metabolism in erythrocyte membrane in asthma. J Asthma 2010;47:966-971.

52 Masini E, Giannini L, Nistri S, Cinci L, Mastroianni R, Xu W, Comhair SA, Li D, Cuzzocrea S, Matuschak GM, Salvemini D: Ceramide: a key signaling molecule in a Guinea pig model of allergic asthmatic response and airway inflammation. J Pharmacol Exp Ther 2008;324:548-557.

-53 Karman J, Tedstone JL, Gumlaw NK, Zhu Y, Yew N, Siegel C, Guo S, Siwkowski A, Ruzek M, Jiang C, Cheng SH: Reducing glycosphingolipid biosynthesis in airway cells partially ameliorates disease manifestations in a mouse model of asthma. Int Immunol 2010;22:593-603.

54 McGovern MM, Aron A, Brodie SE, Desnick RJ, Wasserstein MP: Natural history of Type A Niemann-Pick disease: possible endpoints for therapeutic trials. Neurology 2006;66:228-232.

55 Wasserstein MP, Desnick RJ, Schuchman EH, Hossain S, Wallenstein S, Lamm C, McGovern MM: The natural history of type B Niemann-Pick disease: results from a 10-year longitudinal study. Pediatrics 2004;114:e672-e677. 